\title{
CORRUPCIÓN Y DETERIORO DEL ESPACIO URBANO EN EL DISTRITO FEDERAL
}

\author{
CORRUPTION AND DETERIORATION OF URBAN SPACE IN THE FEDERAL DISTRICT
}

\author{
Mario Ojeda Revah ${ }^{1}$ \\ Alfonso Jiménez de Sandi ${ }^{2}$
}

\begin{abstract}
Resumen
Proponemos como hipótesis que gran parte de la violencia que se vive actualmente en la Ciudad de México ha sido propiciada por la omnipresencia de la corrupción, y por la pasividad del Estado frente a dicho fenómeno. Los gobiernos locales, estatales y federal se muestran incapaces de imponer un Estado de derecho para la convivencia armónica, en los temas más básicos y cotidianos como el tráfico, la basura, la apropiación de espacios públicos por ambulantes, franeleros, empresas de publicidad y sus "espectaculares", el cerco de calles por vecinos, y los bloqueos de vías de comunicación, entre otros.
\end{abstract}

Palabras clave: Corrupción, estado de derecho, abdicación, crímenes, negligencia, simulación, aplicación de la ley

\section{Abstract}

We propose as a main hypothesis that much of the violence that Mexico City is experiencing has been driven by the pervasiveness of corruption, and by the local government inaction against this phenomenon. Local, state and federal governments, all, seem powerless in imposing the rule of law for the peaceful coexistence, in the most basic everyday urban problems, such as traffic, litter, the appropriation of public spaces by street vendors, informal auto cleaners, advertising companies and their "billboards", the arbitrary gating of communities and the blockage of roads, within others.

Keywords: Corruption, rule of law, abdication, crimes, neglect, simulation, law enforcement

\footnotetext{
1 Doctor en Ciencia Política por la London School of Economics (2002), Investigador Titular "A" del Centro de Investigaciones sobre América Latina y el Caribe (CIALC) de la Universidad Nacional Autónoma de México. Profesor de la Facultad de Ciencias Políticas y Sociales de la UNAM. E-mail: ojedarevah@yahoo.com

2 Economista por el ITAM y Sociólogo por la UNAM. Doctorante en Estudios Latinoamericanos de la Facultad de Filosofía y Letras, dónde trabaja su tesis sobre la Política Exterior de Alemania en Nicaragua en el período 1979-1990. Profesor de Políticas Económicas en el Centro de Estudios Políticos de la Facultad de Ciencias Políticas y Sociales de la UNAM, y Profesor de Políticas Educativas y Problemas Contemporáneos de la Educación en la Coordinación de Pedagogía de la Facultad de Filosofía y Letras de la UNAM. E-mail: ajimenezdesandi@netscape.net
} 
El desistimiento por parte de las instancias gubernamentales para hacer respetar las leyes, ha hecho de la corrupción un fenómeno ubicuo, en el que las conductas de gran parte de la población revelan un preocupante desprecio por la legalidad y por las normas mínimas de convivencia. En suma, la corrupción ha acabado por convertirse en anomia. La pregunta se plantea entonces del siguiente modo: ¿Por qué han abdicado los distintos niveles del gobierno mexicano de sus obligaciones y funciones más elementales? ¿Por qué los mexicanos parecemos ser incapaces de cumplir las normas más elementales y comportarnos con sentido cívico?

Una sociedad corrompida, tiende, sin remedio, a la descomposición, la injusticia y, finalmente, a la violencia. Es en ese sentido, que suscribimos y hacemos propia, para los propósitos del presente trabajo, la teoría de las "ventanas rotas" (Kelling y Coles, 1996), que propone arreglar los problemas cuando aún son pequeños, antes de que estos acaben por rebasarnos. Dichos autores sostienen en su célebre ensayo que: el desorden y el crimen están, por lo general, indisolublemente unidos, en una especie de círculo vicioso.

De acuerdo con los autores, tanto los psicólogos sociales como los agentes de policía tienden a coincidir en que si una ventana en un edificio es vandalizada y se queda sin reparar, el resto de las ventanas del mismo pronto serán vandalizadas. Una ventana rota sin reparar es una señal de que nadie se preocupa, por lo que romper más ventanas no sólo no tiene ningún costo o sanción, sino que, lejos de ello, se vuelve un incentivo para delinquir. Un mobiliario urbano sin atención pronto se convierte en presa fácil para la destrucción, por parte de gente que lo hace ya bien "por diversión" o bien por saqueo, e incluso por gente a la que normalmente no se le ocurriría hacer tales cosas y que, probablemente, se consideran respetuosas de la ley.

La reciente crisis de la basura en nuestra urbe es un ejemplo contundente de tal fenómeno. Ante la omisión de las autoridades por atajar el problema en su origen, imponiendo sanciones a los infractores y aplicando a rajatabla el reglamento, el asunto creció de forma descontrolada al grado que proliferaron los tiraderos clandestinos de desperdicios, y el problema rebasó de plano a las autoridades.

Corresponde entonces a las instituciones del Estado el imponer la ley, resolver los problemas en cuanto aparecen, y corresponde a los ciudadanos exigir una rendición de cuentas al Estado por su inoperancia y aparente falta de voluntad en la aplicación de la legalidad cotidiana. Para lograr lo anterior, es condición indispensable asentar y consolidar la estabilidad política y democrática, a través un pacto entre las distintas fuerzas políticas, de manera tal que la acción de la justicia no dependa del color partidista, sino que se transforme en una política de Estado, que promueva un aparato de justicia y seguridad eficaz y que tenga como objetivo la preservación efectiva del orden legal. 
La corrupción termina por materializarse en una concepción pervertida de la sociedad y del individuo. Es necesario un cambio de mentalidad en el que se sancione el enaltecimiento de comportamientos ilegales y de figuras corruptas en el imaginario social. Se requiere de una estructura jurídica sólida, estable, sistemática e innegociable. Una presencia permanente del Estado en casos en los que abiertamente se aliente la ilegalidad, como la componenda, la aplicación selectiva de la ley o los juicios de amparo, los cuales se han convertido en un subterfugio legal para eludir la ley. Es necesaria una ética que contrarreste la atomización social y el individualismo a ultranza y que promueva el sentido comunitario y los valores de justicia social.

Desde el año 2006 México vive una espiral de violencia que lejos de amainar parece ir in crescendo. Gran parte de las bajas causadas por dicha violencia obedecen a la respuesta dada por el crimen organizado a la ofensiva en su contra lanzada por el Presidente Felipe Calderón, desde que comenzó su investidura, en diciembre de ese año. Varios analistas han intentado explicar lo que hoy parece una cruzada fracasada por parte del ejecutivo contra la delincuencia a partir de muy diversos enfoques.

Más allá de la contabilidad de las bajas provocadas por la llamada "guerra contra las drogas", existe otro recuento de los daños no asumido por las autoridades. Se ha omitido llevar un registro de la mortandad creciente provocada por la delincuencia "común" o "crimen desorganizado", que también se ha incrementado en estos años. Es indudable que la impunidad-ambiente-ha incentivado el crecimiento de la violencia. La justicia de nuestro país se ha revelado incapaz de investigar y detener a los autores de los crímenes y presentarlos ante un juez. Se puede alegar, también, que la difusión que los medios de comunicación han dado al tema de la inseguridad, lejos de inhibir la violencia ha devenido, paradójicamente, en una suerte de "efecto demostración", que alienta su crecimiento. No obstante, todo intento por regular los contenidos y la cobertura que han dado los medios de dicho flagelo han sido desechados como un ataque a la libertad de expresión.

Mucho se habló, en el ya lejano año 2000, del "cambio" que habría de vivir México, como resultado de la alternancia política. Se tenía entonces la confianza y quizás la fe, en que el nuevo gobierno emanado de las filas de Acción Nacional, habría de resolver como por ensalmo los vicios heredados y entonces atribuidos al largo predominio del Partido Revolucionario Institucional, tales como la corrupción, la violencia y la impunidad. A doce años de distancia, vemos que tales problemas, no sólo no le eran atribuibles al PRI en exclusiva, sino que formaban parte de una arraigada cultura nacional, y que lejos de resolverse, se han agravado de forma dramática. Se suponía, quizás con ingenuidad, que la alternancia iba a resolver los 
problemas derivados de la corrupción en México, en la medida en que el Partido Acción Nacional se presentaba como la opción "decente", que habría de poner fin a ese Estado de cosas.

El presente trabajo busca sumarse a otras explicaciones sobre el fenómeno de la violencia, refiriéndose específicamente a la Ciudad de México. Pese a que constantemente se afirma que la capital del país no padece las atrocidades de otras entidades y que se trata de la ciudad más segura del país, lo cierto es que la capital padece una criminalidad que-la lleva a estar entre las cinco primeras ciudades con mayor prevalencia delictiva (Ver Cuadro 1).

\section{Cuadro 1}

\section{Prevalencia Delictiva en Personas}

Victimas por cada 100,000 habitantes para la población de 18 años y más en el año 2010, por entidad federativa.

\begin{tabular}{|c|c|c|c|}
\hline Entidad & Víctimas 2010 & Entidad & Victimas 2010 \\
\hline NACIONAL & 23,956 & & the \\
\hline Aguascalientes & 36,387 & Morelos & 21,925 \\
\hline Baja California & 30,753 & Nayarit & 23,224 \\
\hline Baja California Sur & 23,328 & Nuevo León & 27,310 \\
\hline Campeche & 17,321 & Oaxaca & 16,262 \\
\hline Coahuila & 25,250 & Puebla & 21,707 \\
\hline Colima & 17,138 & Querétaro & 19,675 \\
\hline Chiapas & 12,856 & Quintana Roo & 28,740 \\
\hline Chihuahua & 34,826 & San Luis Potosi & 22,636 \\
\hline Distrito Federal & 32,495 & Sinaloa & 26,373 \\
\hline Durango & 20.598 & Sonora & 29.285 \\
\hline Guanajuato & 20,890 & Tabasco & 25,074 \\
\hline Guerrero & 20,172 & Tamaulipas & 22.647 \\
\hline Hidalgo & 20,699 & Tlaxcala & 20,721 \\
\hline Jalisco & 24,452 & Veracruz & 16.437 \\
\hline México & 27,908 & Yucatán & 17,826 \\
\hline Michoacán & 14,931 & Zacatecas & 22,747 \\
\hline
\end{tabular}

Fuente: Mitofsky / Encuesta Nacional de Victimización y Percepción sobre Seguridad Pública 2011 INEG| 
Por otro lado, al igual que las delegaciones políticas de Iztapalapa, Gustavo A. Madero, Cuauhtémoc y Venustiano Carranza, municipios conurbados del Estado de México, como Ecatepec, Naucalpan, Los Reyes La Paz y Netzahualcóyotl, muestran un incremento alarmante en el número de homicidios registrados en su ámbito (Ver Cuadro 2), al igual que un incremento en el robo a casa habitación con violencia. ${ }^{3} 4$

En esta tesitura, es conveniente indicar que la sociedad capitalina no se circunscribe a los límites del Distrito Federal y que, lejos de ello, desarrolla una interacción cotidiana con el Estado de México.

\section{Cuadro 2}

\section{HOMICIDIOS A LA ALZA}

Aunque el número de ejecuciones en la ciudad de México creció ligeramente en 2011, comparado con el año previo, en los municipios mexiquenses que rodean el DF la violencia se aceleró

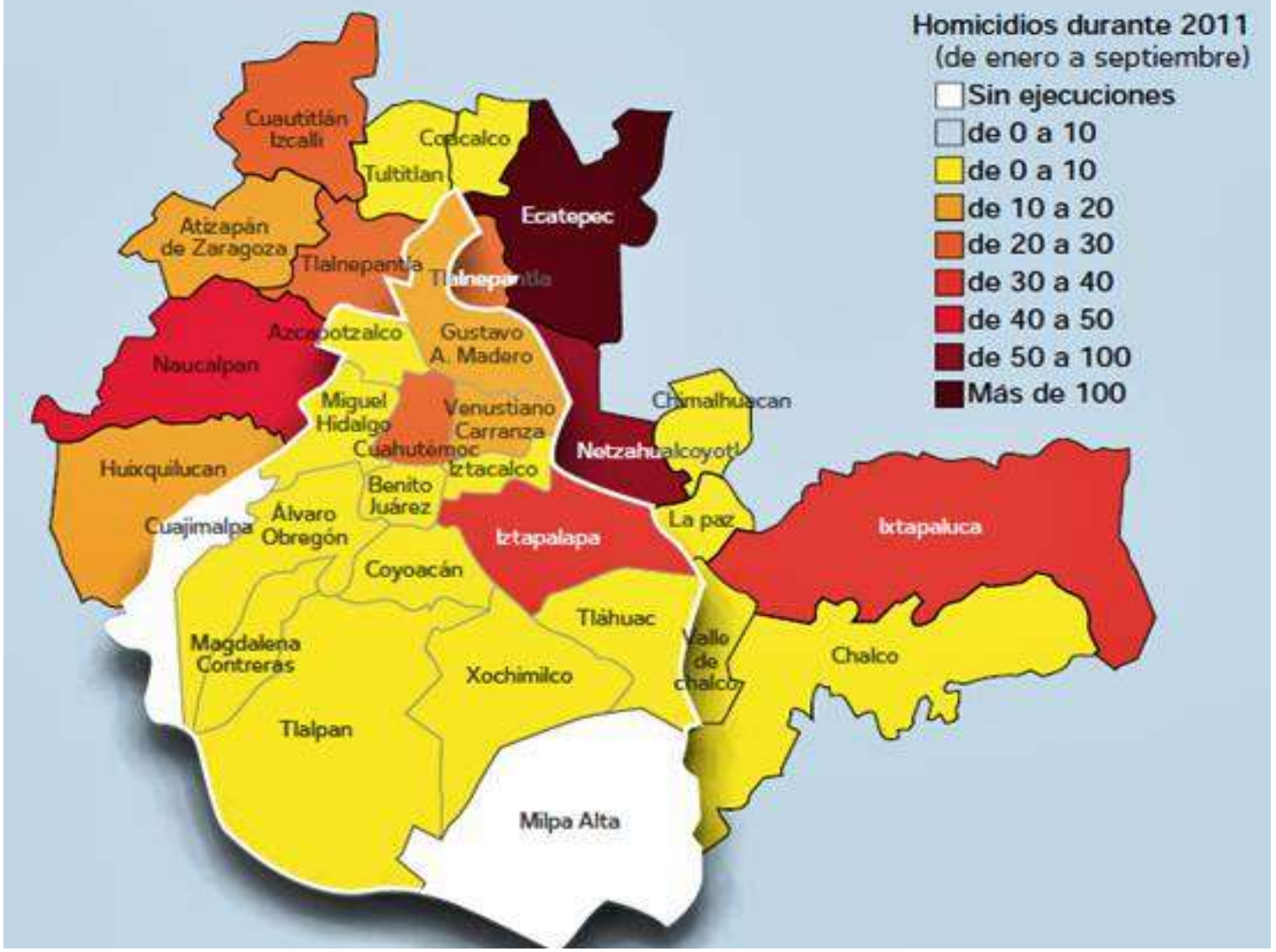

Fuente: El Universal.

\footnotetext{
${ }^{3}$ Este último dato según el Consejo Ciudadano de Seguridad Pública y Procuración de Justicia del Distrito Federal. http://consejociudadanodf.org.mx/
} 
Al revisar los datos es posible cobrar conciencia de los problemas que enfrenta una investigación de esta naturaleza, en virtud de la falta de fuentes y estadísticas confiables; no sólo existe una llamada cifra negra de delitos que no se denuncian, sino también, una mucho mayor, de casos que nunca llegan a resolverse. No obstante, bastaría llevar a cabo un seguimiento somero de la llamada nota policiaca de los diarios capitalinos, para darse cuenta que el tema de la seguridad en el Distrito Federal dista de ser lo óptimo que nuestras autoridades aducen.

\section{PLANTEAMIENTO TEÓRICO}

Proponemos como hipótesis principal de nuestro trabajo que gran parte de la violencia que se vive actualmente en México ha sido propiciada por la omnipresencia de la corrupción, y por la pasividad del Estado, producto quizá de la transición política que llevó a un cierto grado de relajación en la aplicación de la ley, lo que en última instancia degeneró en un alto nivel de ingobernabilidad.

La corrupción es un término que proferimos constantemente, sin parar mientes en su verdadero significado, por lo que, antes de proceder con nuestro trabajo, es menester definirla. En el sector público, el término "corrupción" se refiere al abuso de las facultades de gobierno para el beneficio personal (Nye, 1967), (Ackerman, 1978) y (Kaufmann, 1997). Cuando, por ejemplo, un empleado público solicita dinero a un vecino a cambio de la realización de un servicio público (como recoger la basura, acelerar un trámite, reparar una alcantarilla, etc.) está actuando de forma corrupta. Está usando su posición como servidor público para su beneficio personal. La corrupción, según la define el politólogo norteamericano, Samuel Huntington, (Huntington, 2002: 253), es: "el comportamiento de los funcionarios públicos que se desvía de las normas aceptadas a fin de servir fines privados", es decir es la ausencia de una efectiva institucionalización política, y sugiere que las funciones y las causas de la corrupción son las mismas que las de la violencia, las dos están provocadas por la modernización, vale decir, son síntomas de la debilidad de las instituciones políticas en una sociedad en transición.

Las sociedades que tienen una alta capacidad de corrupción, tienen una alta capacidad de violencia. La transmisión de la violencia sin embargo representa una mayor amenaza a la sociedad que la corrupción misma. Ante la ausencia de acuerdos sobre cuestiones públicas la corrupción establece arreglos sobre objetivos privados, mientras que la violencia sustituye el conflicto sobre asuntos públicos y privados. La corrupción y la violencia son medios ilegítimos para plantear demandas al sistema, pero la corrupción lo es también para obtener dichas 
demandas, mientras que la violencia es un gesto simbólico para protestar, es un síntoma de mayor alienación extrema. La corrupción es funcional al mantenimiento del sistema, al igual que la reforma, lo grave es que la corrupción sustituye a la reforma, y ambas sustituyen a la revolución.

La corrupción puede aparecer, y de hecho aparece, aún en los ámbitos más insospechados de la interacción entre las personas: lo mismo entre particulares, entre particulares y el gobierno o al interior del propio gobierno y ocurre en la combinación de dos factores: el desvío de los valores éticos en la conducta de algunos individuos y en una situación propicia para el ilícito, (López Presa, 1998).

No se trata entonces de un problema menor: la corrupción genera ineficiencia. Un soborno puede facilitar ciertas gestiones pero también sirve como incentivo para que las autoridades ideen nuevos trámites y obstáculos burocráticos. Por esta razón, se ha demostrado con datos duros que en el largo plazo, la corrupción propicia el crecimiento de la economía informal y los mercados negros; disminuye los ingresos tributarios y con ello debilita a las instituciones, y finalmente socava la capacidad de las instituciones judiciales por hacer cumplir la ley. La corrupción provoca mayores ineficiencias en el sistema, lo cual lleva a un menor crecimiento económico, (Hellman, et al., 2000). En el plano económico el fenómeno impide el crecimiento de las empresas estatales y privadas, destruye las relaciones laborales internas y desalienta la inversión. Connotados economistas, como George T. Abed y Sanjeev Gupta, (Abed y Gupta, 2002) muestran también que la corrupción inhibe la inversión y, por ende, inhabilita el desarrollo, pues engendra incertidumbre.

Finalmente, la corrupción distorsiona la democracia, ya que puede más quien esté dispuesto a pagar más y, por ende, recibe más a cambio, lo que redunda en una flagrante inequidad entre los ciudadanos. A ello habría que sumar las distorsiones que el clientelismo y el corporativismo, fenómenos intrínsecamente ligados a la corrupción, generan para la democracia.

Lejos de enfrentar tales prácticas, la transición política acabó por consolidarlas, tal y como testimonian la alianza establecida por el Presidente Calderón con el Sindicato Nacional de Trabajadores de la Educación, a nivel federal, y, en el caso del Distrito Federal, los pactos establecidos por algunas de las corrientes perredistas con sus clientelas, tales como los microbuseros, taxis pirata, ambulantes, etc.

Por otra parte, la transición política tuvo como efecto colateral y no previsto una centrifugación del poder estatal que devino en falta de coordinación y, en última instancia, parálisis. El gobierno federal no ha contado con el apoyo de muchos de los gobiernos estatales, 
los que responden a los intereses de sus partidos y que, por lo tanto, no tienen incentivos para poner freno a la corrupción estatal, hecho que se repite en la relación entre los gobiernos estatales y los municipales. Lo anterior ha generado ingobernabilidad, que en algunos casos ha llevado a calificar la situación mexicana como la de un "Estado fallido" (Grayson, 2010). Esta es la grave situación que vivimos a casi doce años del gobierno del cambio: crisis de violencia e inseguridad, crecimiento insuficiente de la economía, deterioro de las instituciones y un clima de ingobernabilidad, productos todos ellos de políticas públicas federales y locales que han fracasado.

Ello permite hablar de un Federalismo deficiente. Podemos confirmar lo anterior al observar que en México no se han cumplido los mecanismos que hacen que el federalismo sea exitoso. En la práctica el federalismo ha probado ser altamente disfuncional en México. Las diversas autoridades lo invocan simplemente para abdicar de sus responsabilidades, aduciendo que no son de su competencia. Esto lleva a una carrera perversa hacia la incompetencia y a la inmovilidad, en la que las distintas dependencias y los diferentes niveles de gobierno se echan la pelota unos a otros, para declinar de sus obligaciones. Esta deficiente coordinación ha llevado a un peligroso deterioro de la vida social.

Resulta evidente que nuestro federalismo debe actualizarse y convertirse en un régimen basado en una auténtica distribución de competencias y una eficaz coordinación entre los poderes federal, estatal y municipal.

Puede afirmarse que la transición política en México creó condiciones de ruptura institucional, que facilitaron la descomposición política, regional y local. De ahí que se haya acentuado la actuación impune de los delincuentes, ya que al no haber control de los problemas más sencillos, tales como el tránsito vehicular, el ambulantaje, la basura, etc., los grandes crímenes crecieron. En el caso específico del Distrito Federal la falta de comunicación del GDF con el Gobierno Federal y con algunos gobiernos locales (delegaciones políticas) se tradujo en un agravamiento de las condiciones de vida de la ciudad. El caso del Bordo Poniente es un ejemplo contundente de cómo los colores partidistas han pesado más que el bienestar de la ciudadanía. La incapacidad de las distintas fuerzas políticas del país por desarrollar un dialogo político productivo ha tenido altos costos para una eficaz administración pública, hecho que se refleja en falta de seguimiento y continuidad de las políticas públicas, lo que a la postre afecta la gobernabilidad, otorgando nuevo espacios al hampa. 


\section{PARTICIPACIÓN CIUDADANA}

Por otro lado es de justicia recalcar, que lejos de contar con una participación ciudadana, comprometida y responsable, nos encontramos con una abulia generalizada, perpetuada por la falta de confianza en las autoridades, lo que ha instalado un cinismo generalizado en la ciudadanía, (Norris, 2002). México se ha transformado, a decir de Fernando Escalante, en una democracia sin ciudadanos, o bien, en una sociedad con una ciudadanía de baja intensidad; incipiente, que no está a la altura de su tarea, ni de sus responsabilidades. De este modo no sorprende, que estemos ante un escenario en el que diversos grupos sociales exigen el reconocimiento y la garantía de sus derechos por parte del Estado; pero que, al mismo tiempo, omiten en forma deliberada sus obligaciones y el respeto a la norma establecida.

En ese sentido, resulta indispensable revertir la indiferencia y el cinismo de la mayor parte de los ciudadanos, que esperamos que otros afronten y resuelvan las necesidades y problemas sociales, negociando el incumplimiento de la ley. Amplios sectores de la población que organizan motines y bloqueos y exigen demandas de muy difícil cumplimiento, y que al mismo tiempo, no quieren pagar impuestos, apenas confían en las fuerzas del orden público, o en los jueces, recelan de las formas de representación y se buscan la vida más o menos al margen de la ley, considerando tales prácticas como legítimas. Es así que nos encontramos ante la exigencia interminable de derechos: aquellos de la extorsión particularista y de las formas parasitarias de intermediación y clientelismo.

Es obvio que debe potenciarse la participación ciudadana en México. Desafortunadamente, en nuestro país, se legisla mucho, pero se cumple poco, o nada, con lo legislado. ¿De qué sirve tener muchas leyes, supuestamente virtuosas, si al poco tiempo, se abandona su puesta en vigor? Pensemos en los llamados "cruceros de cortesía", mismos que se anunciaron con bombo y platillo, sólo para caer en el olvido. Como único recuerdo de su breve existencia, quedan unos grandes círculos, cada día más borrosos en las grandes intersecciones de nuestra urbe. Lo mismo ha sucedido con las llamadas asambleas ciudadanas que sustituyeron a las asambleas de los antiguos jefes de manzana de los comités vecinales. Se publicó una grandilocuente Ley de Participación Ciudadana ${ }^{5}$, sólo para ser relegada al olvido. Las organizaciones de vecinos deben de ser la base indispensable para optimizar el trabajo de combate al delito, al vincular a los ciudadanos con las autoridades competentes. Desafortunadamente, y a pesar de que la ley lo contempla, no existen en la actualidad

\footnotetext{
${ }^{5}$ Para ver la ley. https://docs.google.com/viewer?url=http\%3A\%2F\%2Fwww.dgpc.df.gob.mx\%2Ffundamentos\%2Fley\%2Fi nfo2006\%2Flpcdf.pdf
} 
mecanismos efectivos de vinculación, ni de rendición de cuenta, toda vez que la corrupción propiciada por el corporativismo y el clientelismo de las asociaciones y organizaciones vecinales se han impuesto a un ordenamiento ciudadano racional. Como bien apunta Carlos Piñeyro Nelson, (Piñeyro, 2007: 7): "en los hechos concretos, todos los mecanismos establecidos en la nueva Ley son funcionales a las estructuras gubernamentales, dado el casi inexistente margen para poder cuestionar $y$, en su caso, cambiar el rumbo de actos o leyes que afectan directamente a la ciudadanía".

Esa misma ley establece que en cada unidad territorial (1292 unidades en todo el DF) "habrá una Asamblea Ciudadana, que se reunirá al menos tres veces por año, será pública y abierta y se integrará con los habitantes de la Unidad Territorial, los que tendrán derecho a voz, y con los ciudadanos de ésta que cuenten con credencial de elector actualizada, que tendrán derecho a voz y voto" (Artículo 75). Pese a sus nobles propósitos es evidente que pocos ciudadanos están informados de estas normas y que aquéllos que si las conocen, no tienen muchos incentivos para participar, tal y como revela su inoperancia en los hechos. Después de once años de la última elección vecinal de muy escasa participación (9.5\%), y luego de quince años de la anterior, también de gran abstencionismo (21.33\%), los habitantes de la Ciudad de México acudieron a las urnas en noviembre de 2011, para votar en 2,650 casillas por 9,000 fórmulas. Los resultados fueron francamente desalentadores, menos del $9 \%$ del padrón registrado se tomó la molestia de emitir su voto. ${ }^{7}$

La organización vecinal anterior, conformada por asambleas de jefes de manzana, tuvo mayor difusión que el modelo actual, dada la cercanía de los vecinos que resultaban electos, ya que lograba generar una representación territorial más pequeña, lo que facilitaba una intensa comunicación vecinal y, por lo tanto, un mejor conocimiento de lo que sucedía en las delegaciones. En ese sentido, es posible hablar de un retroceso en las formas de organización vecinal.

Bajo el esquema actual, las Asambleas Ciudadanas eligen a los Comités Ciudadanos, de cuya coordinación surge la instancia de los Consejos Ciudadanos quienes se deben coordinar con las autoridades delegacionales para, según el artículo 135: "Emitir opinión sobre programas y políticas a aplicarse en el Distrito Federal y en la demarcación territorial; Informar a las autoridades del Distrito Federal y de la Demarcación Territorial sobre los problemas que afecten a sus representados, y proponer soluciones y medidas para mejorar la prestación de los servicios públicos y privados, así como sugerir nuevos servicios; Informar permanentemente a

\footnotetext{
${ }^{6}$ Ver todas las unidades territoriales en: http://www.sideso.df.gob.mx/index.php?id=35

7 “Baja participación en consulta vecinal del DF", en Milenio Diario, 13 de noviembre de 2011.
} 
cada uno de los Comités Ciudadanos sobre sus actividades y el cumplimiento de sus acuerdos." Si este esquema funcionara realmente tendríamos una ciudad menos sucia, sin ambulantaje, mejor iluminada, con policías de tránsito que permitieran una mejor vialidad, con una seguridad más eficiente, mejores señalamientos viales, etc. La realidad es muy distinta.

También la Ley de Participación Ciudadana contempla una Red de Contraloría Ciudadana, lo que permitiría darle transparencia al ejercicio del gasto público, sin embargo en los hechos pocas veces se le da puntual seguimiento, toda vez que está atada a los intereses corporativos, en otras palabras, pocos ciudadanos la conocen y los menos que sí, difícilmente pueden participar, dado que es honorífica y no remunerada. La nueva Ley por otro lado contempla los instrumentos de participación como el plebiscito y el referéndum, con todo, no existe un órgano descentralizado del aparato estatal encargado de decidir sobre la pertinencia o no de los mecanismos de consulta, de manera que es finalmente la autoridad central la que decide, como en la tradición del priismo, que tanto han criticado los gobiernos perredistas.

Otro punto importante de crítica a la Ley es que establece la necesidad de contar con al menos el $0.5 \%$ de firmas del padrón electoral, para poder presentar propuestas de referéndum, plebiscito, iniciativa popular o consulta ciudadana, así como para que algún vecino quiera convocar por su cuenta a una reunión de la Asamblea Ciudadana, lo cual representa poco más de 357 mil firmas, lo como bien afirma Carlos Piñeyro Nelson, representa al menos un mal chiste, pues requiere un esfuerzo que no está en manos del ciudadano común. Frente a esto se ha sugerido que se disminuya a $0.01 \%$, pero no ha habido todavía una modificación en ese sentido.

\section{LA REALIDAD}

La omnipresencia de la corrupción en nuestro país, y en nuestra capital, se puede corroborar a través de indicadores que elaboran algunas agencias, entre las más importantes: Transparencia Internacional. En su Barómetro de Corrupción Global 2010, la organización señala que la corrupción en nuestro país se ha incrementado 75\% en el año 2011 respecto del año anterior. ${ }^{8}$

Por otro lado el nivel de corrupción en México es calificado por la propia organización con 3.0 puntos sobre diez posibles, al nivel de países como Malawi e Indonesia. México se ubica como uno de los países más corruptos de América Latina por debajo de Brasil, Chile, Costa Rica,

\footnotetext{
${ }^{8} \mathrm{Al}$ respecto ver los resultado de la encuesta en la siguiente liga: http://www.transparency.org/policy_research/surveys_indices/gcb/2010).
} 
Panamá, Uruguay, Perú y Colombia, según el índice de percepción de la corrupción de esta mima institución. ${ }^{9}$

Del mismo modo, la sección mexicana de Transparencia Internacional califica a la Zona Metropolitana del Valle de México como aquella que presenta los mayores niveles de corrupción de todo el país. ${ }^{10}$ En cuanto a las delegaciones del Distrito Federal, no existen datos precisos sobre los niveles de corrupción en cada delegación, pues persiste la opacidad, los intereses creados y la falta de rendición de cuentas en las mismas, no obstante, un claro indicador de la corrupción es la expansión desordenada del ambulantaje, el cual se ha dado a partir de la venta de los espacios públicos, cuyo beneficio queda en manos de los propios funcionarios delegacionales que debieran de combatirlo. Tal y como afirma Yenisey Rodríguez Cabrera:

Está muy documentado por la prensa mexicana que los propios inspectores de vía pública, funcionarios y policías federales y locales protegen el crecimiento anárquico de esa actividad. Además, siguen siendo constantes los testimonios de los dirigentes del comercio informal donde se denuncia a los inspectores que pasan la charola a diario (cobran cuotas todos los días), a los policías que extorsionan a líderes o ambulantes así como la venta nocturna de mercancía confiscada que realizan los efectivos de la Agencia Federal de Investigaciones (AFI) y los ofrecimientos de mercancía de contrabando que realizan los funcionarios de las Aduanas.

Por su parte, los inspectores de vía pública son juez y parte. Por un lado deben vigilar que no se expanda el ambulantaje, pero por otro son los que por pagos de 5 a 10 mil pesos, ponen a nuevos vendedores en tal o cual calle del Centro o de otra zona de la ciudad, y les cobran directamente su cuota. Asimismo, estos pueden contratar a madrinas, meritorios o familiares, por medio de los cuales pasan la charola, de 20 a 100 pesos diarios. Se menciona entre los ambulantes a algunos inspectores que a pesar de ganar oficialmente 3 mil o 4 mil pesos al mes tienen residencias y automóviles de lujo, lo que ha sido posible gracias a su habilidad para comprar coordinadores y subdirectores de Vía Pública y garantizar con ello que no sean removidos de sus zonas. Incluso, a sus superiores llegan a darles hasta 20 mil pesos a la semana. Se afirma también que esos inspectores llegan, en algunos casos, a gozar también de la protección del Sindicato Único de Trabajadores del Gobierno del Distrito Federal (SUTGDF), y cuando estos personajes son sorprendidos recibiendo dinero y los consignan, el sindicato los apoya, les proporciona abogados, los sacan y regresan a su puesto, (Rodríguez Cabrera, 2007).

\footnotetext{
${ }^{9}$ http://cpi.transparency.org/cpi2011/results/

10 Índice de Corrupción. Transparencia Mexicana: http//www.transparenciamexicana.org.mx/ENCBG/
} 
La explicación más socorrida acerca de la inacción de las autoridades ante el crecimiento espectacular del ambulantaje en la ciudad ha sido que el comercio callejero constituye una válvula de escape, ante la falta de crecimiento y de generación de empleos por la economía nacional. Lejos de ello dicha proliferación ha terminado por convertirse en una auténtica bomba de tiempo. Lo es en la medida en que en última instancia distorsiona el desarrollo de la economía formal, legal y de desarrollo, como se ha señalado líneas arriba.

A lo largo de dos décadas, la respuesta de las autoridades ante la proliferación del comercio ambulante y ante la conquista de fuerza político-electoral por parte de los dirigentes, ha sido no sólo de absoluta complacencia, sino de franca complicidad. Ni los últimos gobiernos del PRI, que gobernaron la ciudad durante décadas, ni los del PRD, que llevan ya década y media al frente del gobierno de la ciudad, han atacado frontalmente el problema debido a la cantidad de intereses ocultos y connivencias generados al amparo del lucrativo negocio del ambulantaje.

\section{Deterioro del espacio público.}

La falta de mantenimiento del espacio público ha sido, con excepciones puntuales, una constante histórica en la administración pública. En nuestra ciudad se ha dado prioridad a la inauguración, con bombo y platillo, de grandes obras públicas como puentes, vías rápidas, etc., infraestructuras que al poco tiempo son descuidadas, envejecen, se vuelven obsoletas, o quedan sumidas en el más completo abandono, por nuestra nula cultura de preservación. En la Ciudad de México abundan alcantarillas sin tapa, farolas apagadas, pasos peatonales no definidos, aceras rotas, o en malas condiciones, problemas que se van acumulando, sin que ninguna autoridad acuda a darles mantenimiento o contención.

La infraestructura deteriorada va creando un entorno favorable para el crimen y, de alguna manera, alienta su propagación. La permisividad que se le ha dado al tema de la basura ha ido generando una auténtica insurrección de la ciudadanía frente a los reglamentos y disposiciones municipales, al tomarse la ley en sus manos, tal y como testimonia la proliferación de basureros clandestinos en nuestros camellones, parques y plazas. Todo ello va creando un ambiente favorable para la transgresión de la ley, cuyo efecto multiplicador deviene, a la larga o a la corta, en espiral incontenible.

La privatización de lo público convierte el acceso a la ciudad, en la capacidad de usarla y disfrutarla, en una posibilidad cada vez mas condicionada a la disposición del suficiente poder adquisitivo para consumir la ciudad, dentro de espacios que se definen por ser excluyentes y 
cerrados. La crisis del espacio público y la creciente segregación socio-económica y de los espacios privados de las clases que tienen la posibilidad de aislarse dentro de urbanizaciones enrejadas, remiten, por una parte, a una crisis de integración resultado de las condiciones de creciente desigualdad social y de consecuente exclusión de sectores cada vez más amplios de la población; y por la otra, a una crisis de identidad común y falta de empatía, entendidas como la imposibilidad de apropiarse de la ciudad y de identificarse con ella en su conjunto, de allí la necesidad de fortificar espacios privados, dentro de los cuales reconstruir los vínculos de pertenencia y elaborar un sentido de la experiencia urbana. Por lo tanto, la crisis del espacio público no es sólo una crisis de la ciudad, sino también de la urbanidad entendida como la convivencia mediada por la ciudad, es decir, como sociabilidad urbana. En la actualidad el espacio público se encuentra estrechado por las nuevas modalidades del urbanismo. ${ }^{11}$ La imitación extra lógica del modelo norteamericano de comercio, expresado en los llamados malls, ha destruido al pequeño y mediano comercio, cuya presencia en nuestras calles y avenidas propiciaba la socialización y la convivencia de los ciudadanos.

Un enorme problema, muy generalizado y muy arraigado en nuestro país, es la venta callejera de piratería. El paradigma de esta práctica, lo constituye, sin duda, Tepito, uno de los mayores centros del mundo de productos apócrifos, mercancía robada y de venta de contrabando (así como de drogas y armas). Se trata de un mercado perfectamente organizado como centro de distribución, aparentemente políticamente protegido, como puede deducirse fácilmente, tras años de "operativos" que no consiguen poner coto a su actividad ilegal. Existen por lo menos otros 80 "mercados negros" de gran tamaño, y muy conocidos en México. Según algunos cálculos, se estima que hay 44.000 puntos de venta relacionados con la distribución de material apócrifo de toda índole. Los principales centros de distribución de la piratería de discos ópticos son de sobra conocidos por las autoridades policiales: Tepito, Plaza Meave, Eje Central, Plaza de la Computación, Lomas Verdes y Pericoapa

Es del dominio público que se trata de zonas donde no entra la policía. Las redadas en Tepito y otros mercados de productos apócrifos sólo se llevan a cabo durante la noche, ya que las propias autoridades alegan que ejecutar las acciones durante el día no es lo "suficientemente seguro," como para hacer cumplir la ley. ${ }^{12}$ Aun cuando llegan a darse este tipo de operativos, no provocan un impacto real en el mercado, pues las mismas tiendas vuelven a abrir y continúan con su negocio, como si nada hubiera sucedido. En cualquier caso son

\footnotetext{
${ }^{11}$ Alcalde brasileño ve en el deterioro del espacio público la raíz de la violencia, " en La Jornada, México, D.F, 14 de marzo de 2011.

12 Véase, "Polis temen a Tepito", en http://noticias-mexico.com/crimen-narco/polis-temen-a-tepito.html "Evitan multar en zonas peligrosas", en, Reforma, 20 de enero de 2012.
} 
contados, o nulos, los arrestos realizados. No sólo ha aumentado el volumen de la piratería de discos ópticos, en este sistema de mercado, sino que también lo ha su extensión. Los falsificadores utilizan las estaciones de metro, donde hay gran circulación de personas, frente a la mirada complaciente de las autoridades para la venta de CD y DVD pirata.

Estos mercados están muy bien estructurados, pues cuentan con canales de distribución efectiva, lo que indicaría que, en multitud de casos, el crimen organizado está involucrado. Algunos de estos grupos del crimen organizado controlan también la exportación y distribución de la actividad a la mayoría de los países centroamericanos y exhiben un gran potencial para exportar dichas mercancías a los propios EE.UU. y otros mercados de América. El espectacular crecimiento de estos mercados no regulados se perfila ya como un serio desafío, no sólo a la seguridad pública, sino a la propia seguridad nacional y a la viabilidad económica del país. Pese a la gravedad del asunto, hoy por hoy no parece existir ningún freno a su crecimiento y, lejos de ello, muchas autoridades parecen estar coludidas en su expansión.

Ello da cuenta de que no ha existido una voluntad política de parte de las autoridades para hacer frente al problema, o que, en el peor de los casos, existe connivencia de parte de éstas respecto a esos mercados altamente lucrativos. La opacidad que persiste en los cuerpos encargados de la seguridad pública no ha permitido la erradicación de estas prácticas. Una vez más resulta obvia la necesidad urgente de que las distintas fuerzas políticas alcancen un consenso mínimo, que permita generar políticas de Estado, que trasciendan periodos de gobierno y que redunden en la profesionalización y confiabilidad de dichas instancias.

Si los gobernantes no pueden enfrentar el comercio de productos apócrifos, contrabando y mercancía robada, a plena luz del día, ante la mirada de todos, ¿qué se puede esperar que hagan frente al crimen organizado a gran escala y sus lucrativos negocios de trasiego de estupefacientes, robo de autos a gran escala, adulteración de bebidas y medicinas, secuestros o tráfico de personas? Este es, en efecto, el meollo del asunto, si no se puede abatir la ilegalidad micro, ¿cómo se pretende acabar con la ilegalidad macro?

De lo anterior se desprende que es absolutamente necesario que exista un mayor control de los mercados callejeros, tanto a nivel municipal como federal. Es imperativo que cualquier campaña contra la piratería por parte del gobierno incluya como prioridad la reducción de este tipo de redes de distribución.

El Estado ha perdido control. ¿Por qué ha perdido control? Vivimos una constante exigencia de mordidas y dádivas de todo tipo. Existe también una presunción razonable de 
corrupción en las delegaciones políticas que debe de ser atacada con todo el rigor de la ley. ${ }^{13}$ Este sistema ha terminado por arraigar en una especie de subcultura, ampliamente tolerada e incluso, socialmente aceptada.

Las comunidades -o los países - donde se toleran las pequeñas infracciones, en donde la gente sabe que la ilegalidad no tiene consecuencias, mandan la señal de que se puede hacer lo que se quiera y que el infractor puede salirse con la suya, porque no habrá castigo para los transgresores. Actitudes interiorizadas que dan cauce al desprecio por la legalidad, a la confianza en la impunidad, a la seguridad de que se puede hacer lo que sea y que a la autoridad ni le importa, ni está dispuesta a hacer nada al respecto. Evidentemente, debe de imponerse la ley, evitar su negociación o componenda y enviar un mensaje contundente e inequívoco de que su incumplimiento tendrá consecuencias.

\section{LA PASIVIDAD DEL ESTADO}

Sin lugar a dudas, la impunidad es el más graves problema de nuestra ciudad. Según algunos estudios, el 98\% de los delitos cometidos quedan sin resolverse; sólo uno de cada cuatro es denunciado, lo que nos arroja una cifra negra de alrededor de un 75\%, según un estudio realizado por el Tecnológico de Monterrey. De los crímenes denunciados sólo se investiga un $15 \%$, de estos, en solo un $4 \%$ se concluye la investigación y de ellos se castiga sólo un $1.75 \% .{ }^{14}$ Es decir sólo se castiga a menos de dos delincuentes de cada cien.

No es exagerado afirmar entonces que la impunidad se ha tornado escandalosa. Otro estudio, Ilevado a cabo por el Instituto Ciudadano de Estudios sobre la Inseguridad (ICESI) ${ }^{15}$, a partir de una encuesta levantada en 2010, reveló que en el Distrito Federal las víctimas desconfían de las autoridades responsables y consideran que los trámites son prolongados y engorrosos, por lo que denunciar los delitos es percibido como una pérdida de tiempo. No sorprende, por tanto, que en dicha encuesta se afirme que el 78\% de las víctimas no acudió a denunciar. La encuesta mostró también que el 85\% de la población considera a la Ciudad de México como insegura, quedando en segundo lugar de su Índice de Percepción sobre

\footnotetext{
13 "Sigue corrupción en delegaciones, denuncian empresarios y comerciantes, en," La Jornada, México, D.F, 14 de julio de 2011.

${ }^{14}$ Véase Milenio Diario 7 de noviembre de 2010

${ }^{15}$ Véase los estudios del estudio del ICESI aparecido en las siguientes páginas: A.http://www.icesi.org.mx/publicaciones/articulos/2004/impunidad_en_mexico.asp

B.https://docs.google.com/viewer?url=http\%3A\%2F\%2Fwww.amdh.org.mx\%2Fmujeres3\%2Fbiblioteca\%2 FDoc_basicos\%2F5_biblioteca_virtual\%2F7_violencia\%2F20.pdf

C.https://docs.google.com/viewer?url=http\%3A\%2F\%2Fwww.icesi.org.m×\%2Fdocumentos\%2Fencuestas \%2FencuestasNacionales\%2FENSI-7_resultados_nacional_y_por_entidades_federativas.pdf
} 
Inseguridad Pública, sólo por debajo de Chihuahua. Esta cifra coincide con la Encuesta Nacional de Victimización y Percepción sobre Seguridad Pública 2011, llevada a cabo por el INEGI, en donde se observa que el $60 \%$ de los ciudadanos del DF considera insegura su entidad. Ver cuadros 3 y 4 .

\section{Cuadro 3}

\section{Percepción sobre Seguridad Pública}

Percepción de la población respecto de la situación actual que guarda la inseguridad pública en su Colonia o Localidad, Municipio o Delegación y Entidad.

\begin{tabular}{|c|c|c|c|c|c|c|c|}
\hline Entidad & $\begin{array}{l}\text { Colonino } \\
\text { Localidad } \\
\text { tusegura }\end{array}$ & $\begin{array}{l}\text { Municiploo } \\
\text { Delegacion } \\
\text { Inseguto }\end{array}$ & $\begin{array}{l}\text { Entidad } \\
\text { Federativa } \\
\text { Insegura. }\end{array}$ & Entidad & $\begin{array}{l}\text { colonila } 0 \\
\text { Localidad } \\
\text { Insegura }\end{array}$ & $\begin{array}{l}\text { Municipio o } \\
\text { Dalegacion } \\
\text { thsoguro }\end{array}$ & $\begin{array}{l}\text { Entroad } \\
\text { Federativa } \\
\text { Insogura }\end{array}$ \\
\hline NACIONAL & $39.5 \%$ & $60.1 \%$ & $69.5 \%$ & & & & \\
\hline Aguascallentes & $37.1 \%$ & $50.7 \%$ & $60.8 \%$ & Morelos & $48.7 \%$ & $66.7 \%$ & $80.8 \%$ \\
\hline Baja California & $36.5 \%$ & $54.6 \%$ & $58.3 \%$ & Nayarit & $31.3 \%$ & $63.8 \%$ & $79.2 \%$ \\
\hline Baja California Sur & $21.3 \%$ & $35.6 \%$ & $37.1 \%$ & Nuevo León & $45.4 \%$ & $67.3 \%$ & $84.5 \%$ \\
\hline Campeche & $27.0 \%$ & $43.9 \%$ & $51.1 \%$ & Оахаса & $27.5 \%$ & $48.9 \%$ & $73.2 \%$ \\
\hline Coahuila & $34.2 \%$ & $58.4 \%$ & $64.5 \%$ & Puebla & $42.6 \%$ & $56.9 \%$ & $64.5 \%$ \\
\hline Colima & $26.4 \%$ & $49.8 \%$ & $66.0 \%$ & Querétaro & $30.7 \%$ & $33.0 \%$ & $29.7 \%$ \\
\hline Chiapas & $27.0 \%$ & $44.5 \%$ & $38.3 \%$ & Quintana Roo & $42.3 \%$ & $56.3 \%$ & $63.9 \%$ \\
\hline Chihuahua & $44.7 \%$ & $80.4 \%$ & $89.4 \%$ & $\begin{array}{l}\text { San Luis } \\
\text { Potosí }\end{array}$ & $37.9 \%$ & $65.3 \%$ & $76.5 \%$ \\
\hline Distrito Federal & $48.3 \%$ & $63.4 \%$ & $75.5 \%$ & Sinaloa & $34.5 \%$ & $71.8 \%$ & $80.9 \%$ \\
\hline Durango & $40.3 \%$ & $81.7 \%$ & $88.1 \%$ & Sonora & $29.7 \%$ & $42.5 \%$ & $46.1 \%$ \\
\hline Guanajuato & $38.9 \%$ & $51.5 \%$ & $54.3 \%$ & Tabasco & $42.7 \%$ & $71.1 \%$ & $77.8 \%$ \\
\hline Guerrero & $34.1 \%$ & $66.3 \%$ & $72.7 \%$ & Tamaulipas & $37.3 \%$ & $73.9 \%$ & $83.4 \%$ \\
\hline Hidalgo & $36.4 \%$ & $52.0 \%$ & $54.8 \%$ & Tlaxcala & $29.0 \%$ & $39.4 \%$ & $41.5 \%$ \\
\hline Jalisco & $35.1 \%$ & $56.2 \%$ & $71.1 \%$ & Veracruz & $32.6 \%$ & $53.9 \%$ & $65.1 \%$ \\
\hline México & $55,3 \%$ & $73.4 \%$ & $83.9 \%$ & Yucatán & $19.0 \%$ & $27.7 \%$ & $26.4 \%$ \\
\hline Michoacán & $31.5 \%$ & $56.6 \%$ & $76.0 \%$ & Zacatecas & $47.1 \%$ & $73.5 \%$ & $83.0 \%$ \\
\hline
\end{tabular}


Cuadro 4

Percepción de incremento de delitos 2010 vs Percepción a futuro de la seguridad

Percepción sobre el incremento de delitos durante 2010 y su relación con la percepción de mejoria de la seguridad pública en lo que resta de 2011.

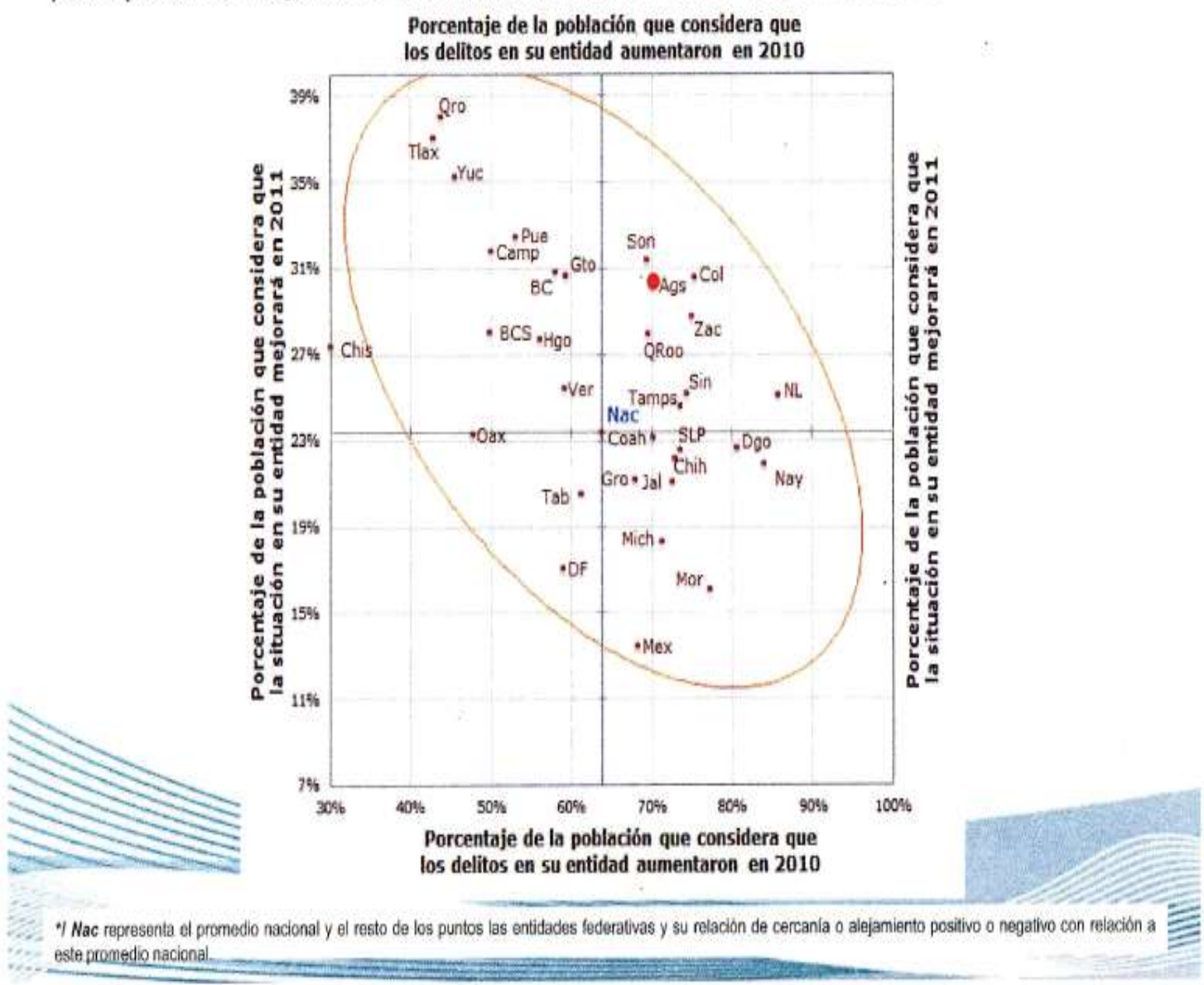

Fuente: Mitofsky / Encuesta Nacional de Victimización y Percepción sobre Seguridad Pública 2011 INEG| 


\section{LAS FUERZAS POLICIACAS}

Desde hace muchos años se suceden las denuncias sobre la corrupción y el involucramiento de los cuerpos policiales en el narcotráfico, el narcomenudeo y los secuestros. Las investigaciones sobre el secuestro y asesinato de Fernando Martí, volvieron a poner al descubierto una trama que ya había sido denunciada una y otra vez, acusaciones que las autoridades capitalinas han ignorado de modo sistemático. De acuerdo con cifras del Secretario Ejecutivo del Sistema Nacional de Seguridad Pública sólo 8 mil 500 policías de los 95 mil con los que cuenta el Distrito Federal, lo que equivale al 9.1 por ciento, han presentado los exámenes de control de confianza. Dichos procesos de control de confianza y disciplinarios siguen basándose en modelos casuísticos, que persiguen elementos corruptos o indisciplinados, en lugar de atacar los problemas estructurales en las instituciones policiales, que permiten y alientan la persistencia de dichas conductas, (Salgado, 2009).

Por otro lado, el gobierno del Distrito Federal se encuentra inmerso en una lógica partidaria, como puede apreciarse en el hecho de que cada vez que se cuestiona la omisión o involucramiento de los cuerpos policiacos del DF en algún delito en la capital del país, tales imputaciones son percibidas como una afrenta a la reputación misma del gobierno capitalino (o, incluso, del PRD), más que como una llamada de atención o alerta, por lo que las autoridades tienden a proteger ( y a encubrir) a los suyos, trátese del News Divine, del secuestro de la Sra. Coppel, o del asesinato del joven Martí. En ese sentido, es la política la que maneja y controla la seguridad; práctica, que en el DF, al igual que en el resto del país, está puesta al servicio de una causa partidaria y no de la ciudadanía.

Diversos factores propician y perpetúan la falta de resultados en nuestras policías. En primer lugar, la corta duración de las administraciones delegacionales y la imposibilidad de reelección de los delegados políticos, dificultan o hacen imposible el seguimiento de políticas de largo plazo, Los políticos cambian, los partidos triunfan y pierden, pero las policías permanecen, los incentivos federales dan prioridad a los pertrechos y a la indumentaria y, en el mejor de los casos, a la capacitación policial, pero no están dirigidos a promover políticas de prevención del delito que incluyan a la ciudadanía, ni, mucho menos, a apoyar modelos de policía comunitaria y vecinal, a pesar de ser contemplados por la Ley de Participación Ciudadana. De hecho, las iniciativas que se han dado en ese sentido, muy pronto degeneran e incurren en la misma corrupción que se pretendía evitar en primer lugar. Tal fue el caso de los llamados policletos, policías de barrio, que al poco tiempo de su introducción acabaron por convertirse en guardias privados de las Ilamadas "tiendas de conveniencia", con cargo al erario público. 
Las autoridades piden que la ciudadanía denuncie las faltas y los delitos, pero una vez que esto sucede, lejos de brindar protección al denunciante, en el mejor de los casos, minimizan su queja, posponen sine die su resolución, en el peor, hostigan a la víctima o, en el colmo de la colusión, comunican la denuncia a los propios infractores, para que estos se hagan cargo del asunto. Prevalece de este modo una suerte de "ley de la selva," en la que gran parte de la sociedad se inhibe de la denuncia, por temor a represalias, u opta por acogerse a la máxima del "sálvese quien pueda".

Resulta urgente plantear una reforma integral de los cuerpos policiacos y las agencias del Ministerio Público, que ataque de raíz el problema. Dar de baja a elementos corruptos, sin sanción ulterior, o levantar un censo que permita su posterior localización, solamente aumenta los potenciales reclutas dispuestos a nutrir las filas de la delincuencia. Tal reforma debe contemplar la creación y/o fortalecimiento de contralorías externas, a cargo de juntas vecinales, organizaciones no gubernamentales y otras iniciativas ciudadanas, lo que permitiría una mayor vigilancia y una mejor rendición de cuentas.

Debe insistirse sobre el hecho de que ciertas conductas y comportamientos asociales debieran de perseguirse y sancionarse de oficio, sin que haya una demanda de por medio; tal es el caso de aquellos que se apropian de las calles, ofrecen un "servicio" y coaccionan a los ciudadanos para que se avengan a pagar. En la actualidad el GDF exige que estos comportamientos sean denunciados, sólo para aplicar una mal llamada "ley cívica", que permite que los infractores vuelvan, una y otra vez. Hemos llegado a un extremo tal de que cuando, tras años de prolongadas y desgastantes deliberaciones, finalmente se instalaron parquímetros en una colonia de la ciudad de México, hubo "un periodo de gracia" e incluso una manifestación de acomodadores exigiendo un "no a la privatización de las calles de la ciudad". La fragmentación de la fuerza policiaca en corporaciones distintas, tales como: auxiliar, preventiva de tránsito, bancaria, turística y hasta charra, no sólo impide la necesaria coordinación, sino que incurre en el mismo vicio de competencias compartimentalizadas, con la abdicación de responsabilidad que ello conlleva. Finalmente, la infiltración de la delincuencia organizada en las instituciones policiales locales pone en riesgo de modo permanente cualquier esfuerzo de reforma de las mismas.

Un ejemplo extremo de la pasividad estatal frente a las conductas asociales, es el hecho incontrovertible que el Reglamento de Tránsito del Distrito Federal sea letra muerta. Una vez más se anuncian grandes medidas, sólo para abandonar su aplicación al poco tiempo. Los semáforos no se respetan, los pasos peatonales son sistemáticamente invadidos, los límites de velocidad son cotidianamente transgredidos. Los microbuses y los taxis pirata se enseñorean de 
nuestras calles, sin que autoridad alguna haga algo por evitarlo. La policía de tránsito simplemente brilla por su ausencia, salvo en instancias en las que exista alguna posibilidad de extorsión o lucro. Las defunciones y lesiones provocadas por accidentes tránsito son ya un problema de salud pública en la capital del país. De acuerdo con datos del Servicio Médico Forense (Semefo) del Distrito Federal la principal causa de muerte en la entidad en 2011 fue resultado de accidentes de tránsito, mucho más que de cualquier otra causa de muerte.

De los tres mil 197 fallecidos que ingresaron a la morgue capitalina de enero a agosto de 2011, un total de 773 correspondieron a muertes por hechos de tránsito, superando con ello la segunda causa de muerte que fue el homicidio, con 746 víctimas. ${ }^{16}$

\section{CONCLUSIONES}

La ciudad de México vive una emergencia, los problemas del agua, la basura, el ambulantaje, el tránsito, la inseguridad y la violencia, entre otras, propiciados por la corrupción y la impunidad, tienen que encontrar prontas respuestas. Para ello se presenta como urgente e impostergable alcanzar un pacto de gobernabilidad entre las distintitas fuerzas políticas representadas en la ciudad, que permitan el seguimiento de políticas de Estado para la Ciudad, al margen de los vaivenes electorales y los cambios de gobierno. Es necesario, también, auspiciar una amplia participación y compromiso ciudadanos, que den sustento democrático a las políticas públicas diseñadas para resolver los complejos problemas de la capital. De no hacerlo, corremos el riesgo de padecer en el futuro inmediato situaciones de violencia como se han observado en el pasado, nos referimos por ejemplo a los linchamientos y demás actos de "justicia" ejercida por propia mano, ejercida por turbas incontroladas contra delincuentes, reales o supuestos, o contra la propia policía, como producto del hartazgo social contra su omisión, simulación o contubernio.

Muchas de las políticas públicas diseñadas y puestas en práctica sin el consenso de la ciudadanía han sido fallidas. Frente a los distintos desafíos que presenta la ciudad, se necesitan acciones concretas que permitan al Distrito Federal pasar a una mayoría de edad. Emprender una verdadera batalla contra la impunidad que permita aumentar los sentimientos de confianza y seguridad de los ciudadanos en las autoridades responsables de la prevención e impartición de la justicia.

Vale reiterar que debe ponerse en marcha una reforma integral de los cuerpos policiacos y de los ministerios públicos, que incluya un censo comprensivo de sus elementos y

\footnotetext{
${ }^{16}$ El Universal, 7 de noviembre de 2011.
} 
un control de confianza que incluya perfiles sicológicos, y que fiscalice medios de vida de agentes y mandos, lo que sin duda inhibiría los actos de corrupción.

La aplicación de la ley sin componendas, aun en faltas menores es la piedra angular sobre la que se debe construir la pirámide de la nueva legalidad. Al prevenir comportamientos antisociales se envía la señal inequívoca de que el quebrantamiento de la ley no será más tolerado. Ello redundaría en una suerte de círculo vicioso, en el que la disuasión y la prevención impidan escaladas criminales.

La participación ciudadana es indispensable para llevar a buen puerto programas eficaces que tengan por objeto terminar con la cultura de la corrupción y con la violencia que ésta genera, con la incompetencia de los organismos públicos que no cumplen con los servicios que les corresponde brindar a la ciudadanía.

Para combatir a la impunidad de una manera eficaz se impone que los gobiernos se abran al escrutinio de la ciudadanía, que la acción de las autoridades que vigilan el cumplimiento de las leyes se despartidice, e impedir que la acción corruptora de las organizaciones clientelares y asociaciones delincuenciales impongan sus agendas y logren sus objetivos, para lo cual es urgente una real y transparente acción de vigilancia ciudadana.

\section{REFERENCIAS BIBLIOGRÁFICAS}

ABED T., George y GUPTA; Sanjeev. Governance, corruption \& economic performance, Fondo Monetario Internacional, 2002.

ACKERMAN, Susan Rose. The Political Economy of Corruption, Institute for International Economics (www.iie.com), 1978.

OLGUIín, Víctor Alarcón.

http://proteccioncivil.uam.mx/difusion/casadeltiempo/21_iv_jul_2009/casa_del_tiempo_elV_n um21_89_91.pdf

CONSEJO CIUDADANO DE SEGURIDAD PÚBLICA Y PROCURACIÓN DE JUSTICIA DEL DISTRITO FEDERAL. http://consejociudadanodf.org.mx/ 
ORTIZ, Enrique Flores. El ataque a la corrupción. Los casos del Distrito Federal y el Estado de México, Instituto Belisario Domínguez del Senado de La República, Dirección General de Estudios Legislativos, Política y Estado, septiembre de 2010, en: http://www.politicayEstadoibd.org/SP/recursos/el_ataque.pdf

GARZA, Gustavo y SCHTEINGART, Martha. Desarrollo Urbano y Regional. México, El Colegio de México, 2010. http://2010.colmex.mx/16tomos/II.pdf

GRAYSON, George W. Mexico: narco-violence and a failed state?, Transaction Publishers, 2010.

HELLMAN, Joel S; JONES, Geraint y Kaufmann. Seize the State, Size the Day: State Capture, Corruption and Influence in Transition, 2000, World Bank Policy Research Working Paper No. 2444

HUNTINGTON, Samuel. Modernization and Corruption, en Arnold J. Heidenheimer, Michael Johnston, Political corruption: concepts \& contexts, New Jersey, Transaction Publishers, 2002. Instituto Ciudadano de Estudios Sobre la Inseguridad (ICESI), las siguientes páginas:

A. http://www.icesi.org.mx/publicaciones/articulos/2004/impunidad_en_mexico.asp

B.https://docs.google.com/viewer?url=http\%3A\%2F\%2Fwww.amdh.org.mx\%2Fmujeres3\%2Fbib lioteca\%2FDoc_basicos\%2F5_biblioteca_virtual\%2F7_violencia\%2F20.pdf

C.https://docs.google.com/viewer?url=http\%3A\%2F\%2Fwww.icesi.org.mx\%2Fdocumentos\%2Fe ncuestas\%2FencuestasNacionales\%2FENSI-

7_resultados_nacional_y_por_entidades_federativas.pdf

KAUFMAN, Daniel, (1997), Corruption: The Facts, Foreign Policy, verano de 1997.

GEORGE, Kelling y Coles, Catherine. Fixing Broken Windows: Restoring Order and Reducing Crime in Our Communities. N.Y, Touchstone, 1996. ISBN 0-684-83738-2

López Presa, José Octavio. Corrupción y cambio, México, Fondo de Cultura Económica, 1998. 
NORRIS, Pippa. La participación ciudadana: México desde una perspectiva comparativa 15 de julio de 2002, en:

http://www.hks.harvard.edu/fs/pnorris/Acrobat/Mexican\%20Civic\%20Engagement\%20Norris\% 20espanol.pdf

NYE, J.S. Corruption and Political Development: A Cost-Benefit Analysis. The American Political Science Review 61.2 (1967): 417-427.

NELSON, Carlos Piñeyro, 2007, La ilusión democrática. Los espejismos de ley de participación ciudadana en la Ciudad de México, en Institut de Recherche et Débat sur la Gouvernance. http://www.institut-gouvernance.org/fr/analyse/fiche-analyse-354.html

CABRERA, Yenisey Rodríguez, 2007, El comercio informal, una afrenta a los poderes establecidos. Vendedores ambulantes en el Centro Histórico de la Ciudad de México, en Institut de Recherche et Débat sur la Gouvernance, en: http://www.institut-gouvernance.org/fr/experienca/fiche-experienca-10.html

SALGADO, Juan. Reforma Policial en la Ciudad de México: Avances y Regresión, Prepared for the conference: Municipal Strategies of Crime Prevention, Woodrow Wilson International Center for Scholars Washington, D.C. December 10, 2009.

http://www.wilsoncenter.org/sites/default/files/5-PONENCIA_--_SALGADO_--_MEXICO.pdf

Prensa

Milenio Diario

Reforma

La Jornada

El Universal 
Revista de Direito da Cidade

vol.07, no 01. ISSN 2317-7721

DOI: http://dx.doi.org/10.12957/rdc.2015.15202

Trabalho enviado em 17 de outubro de 2014.

Aceito em 22 de janeiro de 2015.

Revista de Direito da Cidade, vol.07, no01. ISSN 2317-7721 p.141-165 165 